NBER WORKING PAPER SERIES

\title{
EFFECTIVENESS OF OFFICIAL DAILY FOREIGN EXCHANGE MARKET INTERVENTION OPERATIONS IN JAPAN
}

\author{
Rasmus Fatum \\ Michael M. Hutchison \\ Working Paper 9648 \\ http://www.nber.org/papers/w9648 \\ NATIONAL BUREAU OF ECONOMIC RESEARCH \\ 1050 Massachusetts Avenue \\ Cambridge, MA 02138 \\ April 2003
}

Hutchison is also a Research Fellow at the Economic Policy Research Unit (University of Copenhagen) and a Visiting Scholar at the Center for Pacific Basin Monetary and Economics Studies at the Federal Reserve Bank of San Francisco. The views expressed are ours alone. We thank participants at the West Coast Japan Economic Seminar at UCSD, the Bank of Canada and the NBER Japan Project for valuable comments. We are also appreciative of research assistance by Stephanie Hendrick and for help with acquiring data from Iichiro Uesugi and Sum-Yu Chiu. The views expressed herein are those of the authors and not necessarily those of the National Bureau of Economic Research.

(C)2003 by Rasmus Fatum and Michael M. Hutchison. All rights reserved. Short sections of text not to exceed two paragraphs, may be quoted without explicit permission provided that full credit including Cnotice, is given to the source. 
Effectiveness of Official Daily Foreign Exchange Market Intervention Operations in Japan Rasmus Fatum and Michael M. Hutchison

NBER Working Paper No. 9648

April 2003

JEL No. F31, F33, F42, G15

\section{ABSTRACT}

Japanese official intervention in the foreign exchange market is of by far the largest magnitude in the world, despite little or no evidence that it is effective in moving exchange rates. This paper investigates the effectiveness of intervention using recently published Japanese official daily data and an event study methodology. Focusing on daily Japanese and US official intervention operations, we identify separate intervention "episodes" and analyze the subsequent effect on the exchange rate. Using the non-parametric sign test and matched-sample test, we find strong evidence that sterilized intervention systemically affects the exchange rate in the short-run (less than one month). This result holds even when intervention is not associated with (simultaneous) interest rate changes, whether or not intervention is "secret" (in the sense of no official reports or rumors of intervention reported over the newswires), and against other robustness checks. Large-scale (amounts over \$1 billion) intervention, coordinated with the Bank of Japan and the Federal Reserve working in unison, give the highest success rate

Rasmus Fatum

Department of Marketing

Business Economics and Law

University of Alberta

Edmonton, Alberta

Canada T6G 2R6

rasmus.fatum@ualberta.ca
Michael Hutchison

Department of Economics

University of California, Santa Cruz

Santa Cruz, CA 95064

hutch@ucsc.edu 


\section{$1 \quad$ Introduction}

The effectiveness of sterilized foreign exchange intervention has been the focus of an ongoing and unresolved controversy since the Jurgensen report was published by G-10 central banks almost twenty years ago (Jurgensen, 1983)). In theory, sterilized intervention may be effective, working through portfolio balance, signaling and noise trading channels. However, empirical support for the effectiveness of intervention, usually based on Bundesbank and Fed intervention, is mixed (see Dominguez and Frankel, 1993, and Sarno and Taylor, 2001, for a recent survey of the literature). Nonetheless, policy makers - judging from their actions-- view sterilized intervention as an instrument for policy. Reviewing the empirical evidence, Obstfeld and Rogoff (1996) conclude: "In any event, governments plainly believe that sterilized intervention has its uses, for they continue to practice it despite the lack of any hard evidence that it is consistently and predictably effective" (p. 595).

Empirical studies to date, however, have not analyzed Japanese official intervention data since the Ministry of Finance (MoF) did not make this publicly available until July 2001. The MoF now discloses, with a 1-3 month delay, the day of intervention, the amount of yen intervention (bought and sold by its agent, the Bank of Japan (BoJ)) and the currency of intervention. Whether or not sterilized intervention is effective in Japan is particularly important at the present juncture since, in the current zero interest rate environment, there is seemingly no room for additional monetary policy stimulus to support foreign exchange operations.

More broadly, this is an important omission in our understanding over the effectiveness

of intervention since Japan is by far the largest participant among governments in the foreign exchange market. As Table 1 shows, over the April 1991 - December 2000 period, the BoJ bought (sold) US dollars on 168 (33) occasions for a cumulative amount of $\$ 304$ billion ( $\$ 38$ billion). This dwarfs all other official intervention in the foreign exchange market. For example, Japanese intervention was greater than US intervention over the same period by a factor of more than 30 and is also much greater than the Bundesbank intervention operations (when Bundesbank was responsible for exchange rate policy in Germany). 
Previous studies of Japanese intervention have relied on monthly/quarterly changes in foreign exchange reserves and data on foreign exchange transactions from the supply and demand for funds in Japanese money markets (e.g. Glick and Hutchison, 1994 and 2000; Watanabe, 1994) or, for daily data, newspaper reports of intervention activity (Ito and Roley, 1987; Galati and Melick, 1999; Ramana and Amiei, 2000). As is well known, however, changes in reserves and newspaper reports are unreliable measures and therefore poor proxies for official intervention operations. Another early paper using the newly available Japanese intervention data is a study by Ito (2002). He investigates the profitability of intervention, the authorities reaction function, and intervention effectiveness within the context of a GARCH time series model.

The objective of this paper is to explore the effectiveness of official Japanese intervention operations in moving the exchange rate and whether intervention might be viewed as a useful policy instrument, especially in a period of interest rate inflexibility (e.g. zero interest rates). In order to address the issue of effectiveness, the methodological starting point of this paper follows Fatum and Hutchison (forthcoming) by recognizing that standard time-series techniques are not well suited to the analysis of intervention vis-à-vis the behavior of exchange rates. Exchange rates are typically highly volatile on a day-to-day basis while, on the other hand, intervention tends to come in sporadic clusters - viewed in this light it is perhaps not surprising that time-series based studies tend not to find strong evidence for a systematic link between exchange rate movements and intervention operations. Although standard time-series techniques are somewhat problematic when dealing with data on exchange rates and intervention, the event study approach used in the finance literature fits very well. Specifically, a cluster of intervention operations constitutes a natural candidate for identification as a single event (e.g. the $\$ 11$ billion purchases of USD by the BoJ on November 29-30, 1999). ${ }^{1}$

1 The issue of endogeneity arises in our study (and every intervention study) since the central bank usually takes its queue to intervene on the basis of observed exchange rate movements. We define intervention events as a "cluster" of related days of intervention activity, the final date of which is essentially the manifestation of when the central bank chooses to stop intervening. This "endogeneity" may make intervention appear more effective. However, we argue that the appropriate measure of successful intervention is not the daily instantaneous impact on the 
In this paper we apply and extend the event study methodology developed by Fatum and Hutchison (and applied to Fed and Bundesbank intervention operations in the DM/USD market) to data on Japanese and US intervention in the USD/JPY exchange rate market over the April 1, 1991 to December 31, 2000 period that Japanese data is available. (This defines the period of analysis). By construction, an event study is a very general test of a specific hypothesis and does not have to rely on a structural model of exchange rate determination. This is a desirable feature given the lack of consensus over the appropriate structural exchange rate model, but the drawback is that the particular channel of transmission (if intervention is effective) is not identified.

Using the non-parametric sign test and the matched sample test, evidence in favor of short-term effectiveness is presented. ${ }^{2}$ Moreover, intervention is effective whether or not it is supported by interest rate changes (monetary policy) and whether or not it is "secret" or reported in the newswires. The results are also robust to alternative criteria for "successful" intervention, event definitions and event window lengths. We also find that intervention is most likely to succeed when it is both coordinated (BOJ and Fed) and large scale (over \$1 billion) in magnitude. In the period of near-zero interest rates in Japan (since September 1995), however, intervention operations have not been coordinated and the success rate has declined.

The rest of the paper is organized as follows. The next section discusses the data and the methodology. Section 3 presents the baseline event study results. Section 4 analyzes the effectiveness of intervention when not accompanied by policy interest rate changes and "news" (public announcements and newswire reports of intervention). Section 5 considers the effectiveness of large-scale versus small-scale intervention, coordinated versus uncoordinated intervention, and also changes the baseline event definition in order to perform robustness checks and address the issue of long-run effects of intervention. Section 6 concludes the paper.

exchange rate while the intervention activity is ongoing, but the cumulative effect after its completion. Moreover, the results are not affected when the "post-event window" is expanded to start immediately prior to the intervention operations and end at the last day of the standard postevent window (see section 5).

${ }^{2}$ Short-term refers to the two, five, ten and fifteen day post-event periods during which the exchange rate movement is examined. 


\section{$2 \quad$ Data and Methodology}

\subsection{Data}

Total government intervention in the dollar/yen market is the sum of the Japanese government intervention and Fed intervention. The Japanese intervention variable is daily BoJ sales (negative values) and purchases (positive values) of USD (millions) against JPY in the foreign exchange market. The Fed intervention variable is daily Federal Reserve System sales (negative values) and purchases (positive values) of USD (millions) against JPY in the foreign exchange market. Both variables are official foreign exchange market intervention data, publicly available and provided by the Japanese Ministry of Finance and the Board of Governors of the Federal Reserve System, respectively

Table 1 shows that during the sample period, April 1, 1991 to December 31, 2000, the BoJ intervened in the exchange rate market on a total of 201 days. The BoJ bought USD against JPY on 168 days and sold USD against JPY on 33 days. On most days the magnitude of intervention was substantial, with trades of over USD 100 million and larger dominating (i.e. only 13 trades of less than USD 100 million were reported). By contrast, the Fed intervened in the USD/JPY exchange rate market on a total of 20 days. The Fed purchased USD against JPY on 18 days and sold USD against JPY on only 4 days. Most Fed sales of USD were small scale (less than USD 100 million), while Fed purchases of dollars were somewhat larger but nonetheless almost all under USD 500 million. The exchange rate is the USD/JPY exchange rate, daily quote at noon in New York. ${ }^{3}$

Figures 1 and 2 illustrate the episodic occurrence of Japanese and US interventions in the USD/JPY exchange rate market, respectively, where long periods of consecutive days with no

3 Both the exchange rate of the day of the event (in Tokyo) and the day after the event was employed in order to check the robustness of the results to time zone differences between Tokyo and New York. The results were not affected. We report the results with the same day exchange rate. The other results are available from the authors upon request. 
intervention are separated by clusters of relatively short periods of days where intervention took place. Figure 3 shows the evolution of total (combined) intervention.

\subsection{Defining Events}

The starting point for an event study is to define the event of interest and to identify the period over which the security price is examined. This period is referred to as the event window and it is comprised of the pre-event days (sometimes referred to as the estimation window), the event day

(or days), and the post-event days. ${ }^{4}$ The "intervention events" need to be identified by establishing the event window over which the pattern of exchange rate movements is analyzed. Most events in finance occur only once over a given period of time. In other words, the event takes place on a single day.

Defining each day that the BoJ, the Fed, or both were active in the USD/JPY exchange rate market as a separate event, however, is problematic since intervention frequently comes in "clusters" - several days in a sequence, not necessarily continuous (i.e. several days of continuous intervention may be separated by a few days of "tranquillity," where no intervention occurs, followed by several more days of intervention). A one-day event definition would therefore lead to several instances of pre- and post-event windows around one-day events, during which other one-day events occurred (regardless of the length of the pre- and post-event windows). A seemingly systematic exchange rate movement around one-day events could thus be caused by other one-day events occurring during the pre- and post-event windows, thereby making the event study of little use. Furthermore, a one-day event definition does not help in structuring the data set, nor does it help illuminate the policy intent of intervention at a particular time. For example, the three continuous days of BoJ intervention on 17-19 December 1997 (during which a total of $\$ 8.2$ billion USD were sold in support of the JPY) are naturally viewed as a single event.

A general consideration when defining events is that, if the event period is set too short, then what is actually one policy episode of intervention may be incorrectly identified as two (or 
more) events (and potentially leading to a number of overlapping event windows). On the other hand, if the event period is set too long, then what are actually two policy episodes - separate policy decisions to intervene in the foreign exchange market - may be incorrectly identified as a single event. Fatum and Hutchison (forthcoming) provide a detailed discussion of event study methodology applied to official foreign exchange market intervention.

In this context, an event is defined as a period of days with official intervention in the USD/JPY exchange rate market in one direction (in terms of purchases or sales), conducted by the BoJ, the Fed, or both, and possibly including a number of days with no intervention. A related point is how many consecutive days of no intervention (the "tranquillity" period) that can be allowed for while still considering the surrounding days of intervention to be part of one and the same event. Given the structure of the intervention data, we choose a "tranquillity" period of 5 days for our baseline results (and vary this number in the robustness checks).

The length of the pre-event and post-event periods, respectively, needs to be set long enough to capture a "normal" no intervention performance of the exchange rate. If the length of the periods is set too long, however, a number of instances of overlap of pre- and post-event windows are created. Pre- and post-event window lengths of two, five, ten and fifteen days were applied and the results were found to be robust to either window length. The results with two-day event windows are our baseline, but a summary of the results with other event window lengths is also presented.

\subsection{Defining Successful Intervention}

A final methodological issue is how to define a successful intervention episode. There is no convention on the definition of a successful intervention episode and, rather than relying on a single definition, this study follows Fatum and Hutchison (forthcoming) and applies three alternative criteria). The first criterion of success is simply whether the direction of the movement in the exchange rate is the same as the direction in which the central bank was intervening, e.g.

\footnotetext{
${ }^{4}$ See MacKinlay (1997) for a survey on event study methodology.
} 
does the value of the JPY relative to the USD increase after JPY are purchased? This measure of successfulness is referred to as the "direction" criterion and is formally expressed as follows: An event is a success if either

$$
\left\{\mathrm{E}_{\mathrm{i}}>0 \text { and } \Delta \mathrm{s}_{\mathrm{i}_{+}}>0\right\} \text { or }\left\{\mathrm{E}_{\mathrm{i}}<0 \text { and } \Delta \mathrm{s}_{\mathrm{i}+}<0\right\}
$$

where $E_{\mathrm{i}}$ is the total amount of central bank intervention (positive values represent purchases of USD, negative values represent sales of USD) during event $i$ and $s_{i+}$ is the JPY/USD exchange rate change during the associated post-event window.

The second criterion defines a successful event as one where intervention is associated with a smoothing of the exchange rate movement. This criterion is formally expressed as follows: An event is a success according to the "smoothing" criterion if either

$\{$ the event is a success according to the "direction" criterion $\}$ or $\left\{\mathrm{E}_{\mathrm{i}}>0\right.$ and $\left.\Delta \mathrm{s}_{\mathrm{i}^{+}}>\Delta \mathrm{s}_{\mathrm{i}}\right\}$ or $\left\{\mathrm{E}_{\mathrm{i}}<0\right.$ and $\left.\Delta \mathrm{s}_{\mathrm{i}_{+}}<\Delta \mathrm{s}_{\mathrm{i}-}\right\}$

where $\mathrm{s}_{\mathrm{i}-\text { is }}$ the JPY/USD exchange rate change during the associated pre-event window.

The meaningfulness of both criteria, however, can be questioned if the central banks were to follow a "leaning with the wind" policy, i.e. if the central banks were to intervene in support of an ongoing exchange rate trend (formally expressed as either $\left\{\mathrm{E}_{\mathrm{i}}>0\right.$ and $\left.\Delta \mathrm{s}_{\mathrm{i}-\mathrm{-}}>0\right\}$ or $\left\{\mathrm{E}_{\mathrm{i}}<0\right.$ and $\left.\left.\Delta \mathrm{s}_{\mathrm{i}_{-}}<0\right\}\right)$ as opposed to "leaning against the wind" when the central banks are trying to slow or reverse the trend (formally expressed as either $\left\{\mathrm{E}_{\mathrm{i}}>0\right.$ and $\left.\Delta \mathrm{s}_{\mathrm{i}-\mathrm{i}}<0\right\}$ or $\left\{\mathrm{E}_{\mathrm{i}}<0\right.$ and $\Delta \mathrm{s}_{\mathrm{i}-}$ $>0\}){ }^{5}$ For example, if the JPY is appreciating during both the pre- and the post-event window, an associated purchase of JPY - even if in reality completely ineffective - is deemed a success according to the "direction" as well as the "smoothing" criterion. Using the same example, 
suppose the rate of change is actually smaller after the intervention event, i.e. the exchange rate still moves in the intended direction but at a lower pace than before the intervention occurred, it seems counterintuitive to denote such an event successful.

In order to accommodate these potential shortcomings of the applied definitions the analysis also distinguishes between "leaning with the wind" and "leaning against the wind" events by conditioning each event on the exchange rate movement of the associated pre-event window.

When the "direction" criterion is applied to "leaning against the wind" events only, the resulting measure of success has a clear meaning in terms of reversing the exchange rate trend that prevailed up until intervention occurred. This particular measure is denoted the "reversal" criteria.

\subsection{Test Statistics}

Two statistical tests are employed. The first test is the non-parametric sign test for the median. This statistic verifies whether the "directions" or the "reversals" in the direction of the exchange rate change following intervention events (e.g. from appreciation during the pre-event window to depreciation during the post-event window), or "smoothing" of the exchange rate change following intervention events (e.g. smaller appreciation) are random or systematic. The sign test for the median is applicable to any continuous distribution and the null hypothesis is that the population corresponding to the sample has a median value equal to zero against the alternative that the median is larger than zero.

With reference to the "direction" and "reversal" criteria for success, if the hypothesis is true, the probability $\rho$ of observing a positive value ("success") is the same as that of observing a negative value ("no-success"), hence $\mu=0.5$. In other words, the random variable X (equal to the number of positive values or "successes") among $\mathrm{n}$ sample observations has a binomial distribution with $\mu=0.5$. A significant sign test indicates that the observed number of successes is

${ }^{5}$ Since the motivation for central bank intervention is rarely announced, the policy criteria "leaning against" and "leaning with" the wind are only indicative of actual policy intentions. 
not a random finding attributable to the equal probability of appreciation or depreciation. For details on this test in event studies, see MacKinlay (1997). ${ }^{6}$

The second test is the matched sample test (see, for example, Ben-Horim and Levy, 1984, p. 458). This one verifies whether there is a significant shift in the exchange rate change between the pre- and the post-event periods. Since it is straightforward to match the observations of one sample (before) with the observations of the second sample (after), the matched sample test can be applied to the event study set-up. The matched sample test is identified with the "smoothing" criterion since it indicates, at the minimum, smaller JPY appreciation or depreciation.

\section{The Results of the Event Study}

Focusing first on the two-day pre- and post-event window definitions (and the maximum 5-day "tranquillity" period), Table 2 identifies 43 intervention events over the 10 -year period. The table provides a detailed description of the behavior of the USD/JPY exchange rate during the pre- and post-event windows, the total amount (and direction) of the intervention for each event, and the number of days of intervention during the events.

The BoJ, the Fed, or both intervened in the USD/JPY exchange rate market on 43 separate events, and 28 of these cases consisted of multiple days of intervention operations. Comparing the direction of intervention during the event with the change in the exchange rate over the preceding period, the two-day pre-event window, 34 events appear consistent with a "leaning against the wind" intervention policy and, accordingly, nine events appear in line with "leaning with the wind".

Turning to the successfulness of the defined events, it is immediately apparent that the direction of the change in the exchange rate during the post-event window was consistent with the direction of the associated intervention in 31 events. In other words, 31 of the 43 events were

${ }^{6}$ Despite the usefulness of the non-parametric rank test in event studies, see MacKinley (1997) and Campbell and Wasley (1993) for details, the relatively small number of events in our samples 
successful according to the "direction" criterion. Furthermore, 24 of the 34 "leaning against the wind" events were successful according to the "reversal" criterion while 29 of the 34 "leaning against the wind" events were successful according to the "smoothing" criterion.

\subsection{Sign Test Results}

Table 3 displays the results from the sign test based on the "direction", the "reversal", and the "smoothing" criterion for successfulness of an event. For the case of the "direction" criterion, the table divides the 43 events into USD purchases ( 29 events) and sales (14 events). 22 of the 29 events of USD purchases were successful thus rejecting randomness at the 99 percent significance level. Only 9 of the 14 events of JPY sales were successful - thus the exchange rate movements subsequent to the intervention operations appeared to be random. Without distinguishing between purchases and sales of USD, 31 of the 43 events were successful, rejecting randomness at the 99 percent significance level.

Based on the "reversal" criterion, and thus the sub-set of events associated with a "leaning against the wind" policy, 17 of the 23 events of USD purchases when the USD had been depreciating were successful, rejecting randomness at the 95 percent significance level. 7 of the 11 events of USD sales when the USD was appreciating were successful, so that randomness could not be rejected. Accordingly, 24 of the 34 events of either USD sales or purchases were successful thus rejecting randomness at close to the 99 percent significance level.

Finally, the sign test based on successfulness according to the "smoothing" definition finds that 20 (9) of the 23 (11) events of USD purchases (sales) associated with a "leaning against the wind" policy were successful, but that randomness could not be rejected at conventional significance levels (based on a binominal distribution with the probability of an individual success of $75 \%$ ). Randomness could also not be rejected for purchases and sales taken together, despite the fact that 29 of the 34 "leaning against the wind" events were successful.

precludes this test. 
As an illustration of the findings being robust to pre- and post-event window lengths other than two days, Table 4 provides a comparison of the sign test results based on window lengths of two and five days. ${ }^{7}$ (The rows identified with "excl. interest rate changes" are discussed in the next section). The results with 5-day windows are stronger than with 2-day windows. With respect to every criterion of success, randomness was rejected at the 99 percent significance level using the 5-day event window. Over a period of 5 days, the success of intervention operations is striking. In particular, it is noteworthy that the "smoothing" criterion is also met for intervention success with the 5-day event window.

Summarizing the findings of this part of the analysis, the null hypothesis of no link between the intervention events and the subsequent short run exchange rate movements is clearly rejected. These results are robust to changes in the length of the pre- and post-event windows and the criteria for success applied as well as to exclusion of "leaning with the wind" observations from the sample.

\subsection{Matched Sample Test Results}

Table 5 presents the results of the matched sample test of the "smoothing" criteria for intervention success. Before (after) the intervention events when the two authorities (BoJ and Fed) purchased USD in the foreign exchange market the average exchange rate change was $0.84(-0.28){ }^{8}$ Before (after) the intervention events when the two central banks sold USD in the foreign exchange market the average exchange rate change was $-0.32(0.26)$. Events of "leaning against the wind" intervention in the USD/JPY exchange rate were, on average, associated with a reversal of the preceding trend. Formally, both cases strongly reject (at the 95 percent significance level or higher) the null hypothesis of no difference in means - that is, intervention appears to have had a smoothing effect on exchange rate changes.

\footnotetext{
${ }^{7}$ Longer window lengths are problematic as expanding the window length beyond the maximum allowed "tranquillity" days creates several overlaps of pre-and post-event windows.

${ }^{8}$ Focusing on the events associated with a "leaning against the wind" policy.
} 
The applied matched sample test, as already noted, assumes normality in the underlying distribution of pre- and post-event window exchange rate changes. There is substantial evidence, however, that exchange rates exhibit a high degree of kurtosis ("fat tails"). This implies that the

normality assumption would lead to a bias towards rejecting the null hypothesis of no difference in mean values. To address this concern, we regress our sample of leaning against the window "matched pair" differences (for both USD sales and USD purchases) on a constant term using White's (1980) heteroskedasticity-consistent (robust) standard errors. The estimated constant term for the differences in matched pairs USD sales (USD purchases) regression is the same as the mean values reported in Table 5, of course, and the p-value is $0.01 \%(0.00 \%)$. These results are thus consistent with the matched sample tests reported in Table 5.

\section{Intervention Success and "News"}

Up to this point, exchange rate movements during the post-event windows are implicitly attributed to central bank intervention and no controls are made for the arrival of other economic news or policies. That is, the event study methodology assumes that intervention defines the event and is not systematically linked to other relevant economic news or developments such as monetary policy shifts. In principle, this is an issue arising in all event studies but is a greater concern in cases such as ours where the event may be drawn out over several days.

In this context, changes in interest rate policy and formal announcements that the $\mathrm{BoJ}$ has intervened would seemingly be the most likely economic developments systemically related to intervention policy. The former "news" is especially relevant under present conditions-- if seemingly successful interventions in Japan were in reality attributable to simultaneous and supporting interest rate changes, this channel is now cut off (on the downward side) with the zero interest rate policy. Under these circumstances, intervention may not be effective. (Intervention with simultaneous interest rate changes may be interpreted as unsterilized intervention). The second point is also of interest, however. Is "secret" intervention (e.g. no official reports or 
rumours of intervention over the newswires) as effective as reported intervention operations in moving the exchange rate?

\section{1 Interest Rate "News"}

To address the first point, we investigate in table 6 the way short-term interest rates controlled by the Fed and the Bank of Japan are correlated with our intervention events. 6 events in our combined intervention (Fed and the Bank of Japan) sample were also associated with interest rate changes by either the Fed or the $\mathrm{BoJ}$ at some point during the sample period. The second column shows the interest rate changes during each event (JPD indicates discount rate changes by the BoJ;

FF denotes Federal Funds rate changes by the Federal Reserve). The third column shows the amount of intervention during the event (positive values indicate purchases of USD against JPY by either the Fed or BoJ). The fourth column shows the date of the interest rate change and the last column indicates whether the interest rate change is in a direction consistent with the intervention operation during the event.

This analysis indicates that only half of the interest rate changes are consistent with the intervention operations during the event period. For example, the $\$ 10.9$ billion USD purchases (sales of JPY) on September 6-8, 1995 were consistent, in the sense of an attempt to weaken the value of the yen in the foreign exchange market, with the 50 basis point decline in the Bank of Japan's discount rate on September 8. On the other hand, the BoJ discount rate drop on July 27, 1992 was not consistent with the $\$ 374$ million USD dollar sales (JPY purchases) on the foreign exchange market.

To isolate the effect of intervention alone (i.e. without interest rate changes), we separate out those events during which no interest rate changes took place. This provides a subsample of 37 "pure" intervention policy events. These results, reported in table 4 (denoted by "excl. interest rate changes"), also support the hypothesis that intervention events are associated with significant exchange rate changes. The results are almost identical to the tests where interest rate changes are included (although with fewer degrees of freedom, statistical significance is 
lowered slightly). Intervention is again significant at conventional levels in every case except in the case of the "smoothing" criteria with 2-day windows. Whether the interest rate changes are included or not does not materially change the results.

These results indicate that, at least in the very short run, intervention policy is effective in moving the exchange rate without supporting interest rate changes. Intervention may not be an alternative to an effective monetary policy since there is only evidence (in our event study) of effectiveness over a horizon measured in terms of the number of days, not weeks or months. Nonetheless, intervention would appear to be effective in moving the exchange rate in the present circumstances - as the BoJ follows a zero-interest rate policy. This is consistent with Svensson's (2001) proposal that the BoJ make an aggressive move to depreciate the exchange rate in attempt to counteract price deflation and recession.

\subsection{News reports of intervention: Is "secret" intervention effective?}

We also investigated the extent to which intervention reported by the authorities, or market rumors of intervention, are responsible for the evidence of intervention's effectiveness in moving exchange rates. We conduct event studies excluding intervention news, and are able to address whether "secret" intervention is effective. News reports were gleaned from the Wall Street Journal (from previous day Reuters newswire reports), and dated to reflect the day the news was available to the market.

Table 7 shows the basic event study methodology, for both 2- and 5-day windows, where events are excluded if intervention "news" was reported simultaneously. The two types of intervention news that would exclude an event are reported intervention as well as "rumours" of intervention. In this sense, the event study in table 7 shows the effects of "secret" intervention. A very high percentage of the events reported in table 7 are "successful" but statistical power is low due to the reduced degrees of freedom. For example, we excluded (due the simultaneous news) 34 of the 43 events in the "direction" test, leaving only 9 events in the sample. 7 of the 9 events were 
successful using 2-day windows according to the direction criterion ( $78 \%$ success rate), but this is only significant at the $90 \%$ level of confidence due to the small number of observations.

Looking across the three tests, two types of news categories, and two window definitions, we observe that intervention was successful in $67 \%$ to $100 \%$ of the events. This number is similar to the results when "news" events were not excluded. However, the p-values range from $1.95 \%$ to $84.38 \%$ due to the low degrees of freedom. On balance, given the low power of the tests, formal statistical tests may not accurately reflect the relative success of "secret" intervention operations. Reports and rumors of intervention usually accompanied actual intervention operations in Japan, making it difficult to disentangle the relative efficacy of open and secret intervention operations.

\section{Large-scale and Coordinated Intervention, Robustness and Long Run Effects}

\subsection{Coordinated Intervention and Magnitude Effects}

It is reasonable to assume that coordinated ( $\mathrm{BoJ}$ and $\mathrm{Fed}$ ) and/or large scale official foreign exchange market intervention operations are likely to have a high probability of success than other forms of intervention. To address the first point, we divide the 43 events into those that were coordinated between the BoJ and the Fed and those that were not (unilateral intervention operations). 12 of the 14 coordinated intervention operations were successful in moving the exchange rate in the desired direction (using the standard 2-day window and direction criterion for success), giving a p-value of 0.65 percent. By contrast, 19 of the 29 uncoordinated events were successful ( $p=6.80$ percent). (This compares with 31 successes out of 43 events overall). The results indicate the probability of success is much higher when the BoJ and the Fed work together in coordinating their intervention operations in the foreign exchange market. ${ }^{9}$

Large-scale intervention operations are also more effective than small-scale operations. Dividing the sample into intervention operations larger than \$1 billion USD (31 events) and less 
than $\$ 1$ billion USD (12 events) give rough measures of "large" and "small" scale. 23 of the 31 large-scale intervention events were successful ( $p=0.53$ percent), compared with 8 of the 12 smallscale intervention events ( $\mathrm{p}=19.38$ percent $)$.

Finally, we investigate whether large-scale coordinated events are the most successful. Using the same definitions as above, we find 12 of the events were both large-scale and coordinated by the BoJ and the Fed and that 11 of these events were successful ( $\mathrm{p}=0.32$ percent). Ninety-two percent of the events were successful in moving the exchange rate in the desired direction when both the BoJ and the Fed were involved, and intervened with substantial amounts of foreign exchange. By contrast, only 8 of the 12 events that were both small-scale and uncoordinated were successful ( $\mathrm{p}=19.38$ percent). Uncoordinated small-scale intervention does not appear to be a useful policy.

\subsection{Robustness Checks: Event Length, Window Length and Endogeneity}

A natural question that arises is whether the results are robust to changes in the length of the event. That is, do short events have different effects than long events in terms of the number of business days that the central bank is actively intervening in the foreign exchange market? To address this issue, we divide the events into "short" (no more than five business days) and "long" (longer than five business days) events. 31 (12) of the events are classified as short (long) in duration. Using our baseline model and the direction test, we find that 22 of 31 short events (9 of 12 long events) are successful with a p-value of 1.47 percent ( 7.30 percent). Both short- and longduration events are successful-- the results are not affected by the number of business days that the central bank decides to intervene in the foreign exchange market.

The analysis to this point is based on an event definition where intervention operations separated by more than 5 consecutive days of no intervention were considered part of different events (the 5-day "tranquillity" definition). In order to check the robustness of the previous results

9 This finding appears consistent with Fatum (2002) who, using a logit model framework, shows that intervention in the USD/DEM exchange rate is more likely to be successful when both the 
we now apply an alternative event definition where intervention operations separated by as many as 15 consecutive days of no intervention are still considered part of the same event (a 15-day "tranquillity" definition). Allowing for 15 consecutive days of no intervention in our event definition reduces the number of events in the sample, thereby lowering the power of the sign test and, therefore, makes the null hypothesis of ineffectiveness harder to reject. Furthermore, this alternative event definition allows for an extension of the pre- and post-event windows to span 15 days without the post-event (pre-event) window of one event coinciding with intervention operations of the subsequent (previous) event.

Table 8 shows the sign test results for four different window lengths $-2,5,10$ and 15 day window lengths - based on the alternative 15 day "tranquillity" definition. With respect to the "direction" criterion, randomness was rejected at the 99 percent significance level for all four window lengths while randomness was rejected at the 95 percent significance level or better when focusing on the "reversal" as well as the "smoothing" criterion. Despite the lower number of events, the previous findings are strongly robust to changes in the event definition.

Finally, the issue of endogeneity was raised earlier in the article: Is intervention really successful or is it simply the case that the central bank continues to intervene until the exchange rate turns in the favorable direction and then it stops intervening? Standard event studies look at the asset price level or change during the post-event window, compared to the pre-event window. However, in our study events typically last several days, so that endogenity of the event (after the initial intervention) may become an issue. To see if our results are changed by events with multiple days of intervention operations, we expand the post-event window to include the event itself and measure the exchange rate change from the start of intervention through the end of the five-day post-event window. Using this modified post-event window (and the standard direction test), we find that 28 of the 43 events are successful with a p-value of 3.3 percent. ( 26 of the 43 events are successful using a two-day post event window combined with the event period). Events with multiple days don't qualitatively affect the results. Measured from the point of intervention 
to the end of the post-event window, central bank intervention moves the exchange rate in the direction intended.

5.3 How long lasting is the effectiveness of intervention?

Our criteria for a successful event focus on the short run, i.e. the two to five day windows before and after each event when using the 5-day tranquillity definition and the two to fifteen day windows before and after when using the 15-day tranquillity definition. Beyond the 15-day window length, we have not addressed the question of whether intervention events appear to have any lasting effect. In order to address this question, we use the 15-day "tranquillity" event definition and extend the pre- and post event windows of our event study set-up to span 30 days.

"Long run" success is thus defined as an average exchange rate movement over a period of 30-days following, and consistent with, the associated intervention event. Extending the analysis to encompass this long of an event window comes at a cost, however, since a number of the intervention events are necessarily excluded due to the overlap of post-event windows and subsequent events. Furthermore, the longer the event window the more likely that other news may influence exchange rate developments. Nonetheless, using the 30-day window and again applying the sign test to the three criteria of success (direction, reversal or smoothing), we can no longer reject the null hypothesis (no effect). In particular, the number of successful events does not exceed the 90 percent confidence level for any of the 9 tests (three criteria of success applied to all events, purchases of USD only and sales of USD only). Although these "long run" results should be interpreted with caution due to the limited sample size, it is clear that evidence in support of effective intervention is absent when the window-lengths are extended to 30 days.

\section{Conclusion}

Japanese official intervention in the foreign exchange market is by far the largest magnitude in the world, despite little or no evidence that it is effective in moving exchange rates. Up until recently, however, official data on intervention has not been available for Japan. This paper investigates the 
effectiveness of intervention using recently published official daily data and an event study methodology. The event study better fits the stochastic properties of intervention and exchange rate data, i.e. intense and sporadic bursts of intervention activity juxtaposed against a yen/dollar rate continuously changing, than standard time-series approaches.

Focusing on daily Japanese and US official intervention operations, we identify separate intervention "episodes" and analyze the subsequent effect on the exchange rate. Using the nonparametric sign test and matched-sample test, we find strong evidence that sterilized intervention systemically affects the exchange rate in the short-run. This result holds even when intervention is not associated with (simultaneous) interest rate changes and regardless of whether or not intervention is "secret" (in the sense of no official reports or rumors of intervention reported over the newswires). Controlling for endogenity (when the central bank intervenes for multiple days during a single event) also does not affect the results. Large-scale intervention operations characterized by the simultaneous presence in the foreign exchange market by both the Bank of Japan and the Federal Reserve gave by far the highest likelihood of success. Over ninety percent of the interventions of this form (large scale and coordinated) were successful in our data sample.

Intervention was also found to be effective even if not accompanied by supporting interest rate changes. This is relevant for present circumstances in Japan where the Bank of Japan is following a zero interest rate policy and there is no room to lower interest rates further. This result suggests that the Bank of Japan could indeed engineer exchange rate depreciation (thereby counteracting deflation and recession) even though interest rates cannot be moved further downwards. However, only one of the fifteen BoJ intervention episodes has been coordinated with the Fed since September 1995 (when Japanese interest rates reach 0.50 percent and subsequently fell to zero). This may explain why the success rate for intervention events has not been high during this period (only 9 successful intervention for a success rate of 60 percent). Under these circumstances, it would appear that only persistent, large-scale and coordinated intervention (Bank of Bank and the Federal Reserve) would seem likely to effect a sustained movement in the exchange rate. 
In interpreting the results two caveats should be noted. First, we only find support for short-run effectiveness of intervention. The baseline results found intervention events to be effective over a period of 2-5 days, and an extension of the framework showed effects lasting for up to two weeks. This is not direct evidence against longer-term effects, but reflects a limitation of the event study methodology. Second, the event-study methodology does not allow identification of the particular channel through which intervention works. Our findings are consistent, however, with recent literature interpreting intervention as a means to "signal" not only future policy but also the central bank's views on the fundamental/equilibrium value of the exchange rate. 


\section{References}

Ben-Horim, Moshe and Haim Levy: Statistics: Decisions and Applications in Business and Economics. Second Edition. Random House (New York). 1984.

Campbell, Cynthia J. and Charles Wasley: "Measuring Security Price Performance Using Daily NASDAQ Returns." Journal of Financial Economics 33:1 (February 1993), pp. 73-92.

Dominguez, Kathryn M. and Jeffrey A. Frankel: Does Foreign Exchange Intervention Work? Institute for International Economics (Washington, D.C.). 1993.

Fatum, Rasmus: "Post-Plaza Intervention in the DEM/USD Exchange Rate", Canadian Journal of Economics 35:3 (August 2002), 556-567.

Fatum, Rasmus and Michael M. Hutchison: "Is Sterilized Foreign Exchange Intervention Effective After All? An Event Study Approach”, UCSC Working Paper No. 02-02 (August 2001). Forthcoming, The Economic Journal (April 2003).

Galati, Gabriele and William Melick: "Central Bank Intervention and Market expectations: An Empirical Study of the Yen/Dollar, 1993-96”, BIS Working Paper no. 77 (October 1999).

Glick, Reuven and Michael Hutchison: "Monetary Policy, Intervention and Exchange Rates in Japan," in R. Glick and M. Hutchison (editors) Exchange Rate Policy and Interdependence: Perspectives from the Pacific Basin Cambridge University Press (Cambridge, United Kingdom), 1994 (chapter 10, pp. 225-257).

Glick, Reuven and Michael Hutchison: "Foreign Reserve and Money Dynamics with Asset Portfolio Adjustment: International Evidence," Journal of International Financial Markets, Institutions and Money 10 (2000), 229-247.

Ito, Takatoshi: "Is Foreign Exchange Intervention Effective? The Japanese Experience in the 1990s,” NBER Working Paper No. 8914 (April 2002).

Ito, Takatoshi and Vance Roley: "News From the US and Japan: What Moves the US-Yen/Dollar Exchange Rate," Journal of Finance, 1987.

Jurgensen, P.: "Report of the Working Group on Exchange Market Intervention (Jurgensen Report)", Washington, Treasury Department (March 1983).

MacKinlay, A. Craig: "Event Studies in Economics and Finance." Journal of Economic Literature 35 (March 1997), pp. 13-39.

Obstfeld, Maurice and Kenneth Rogoff: Foundations of International Macroeconomics, MIT Press, Massachusetts (1996).

of Monetary Economics 14, 1984, pp. 133-150.

Ramaswamy, Ramana and Hossein Samiei: “The Yen-Dollar Rate: Have Interventions Mattered?", IMF Working Paper No. 00/95 (2000).

Sarno, Lucio and Mark P. Taylor: "Official Intervention in the Foreign Exchange Markets: Is it Effective and, If So, How Does It Work?", Journal of Economic Literature 34, (2001) pp. 839868. 
Svensson, Lars E.O. "The Zero Bound in an Open Economy: A Foolproof Way of Escaping from a Liquidity Trap," Monetary and Economic Studies 19(S-1), February 2001, 277-312.

Watanabe, Tsuomu: "The Signaling Effect of Foreign Exchange Intervention: The Case of Japan," in R. Glick and M. Hutchison (editors) Exchange Rate Policy and Interdependence: Perspectives from the Pacific Basin Cambridge University Press (Cambridge, United Kingdom), 1994 (chapter 11, pp. 258-286).

White, Halbert: "A Heteroskedasticity-Consistent Covariance Matrix and a Direct Test for Heteroskedasticity," Econometrica, 48, 1980, pp. 817-838. 
Table 1

Fed and BoJ Intervention in the USD/JPY Exchange Rate Market

Bank of Japan Intervention, April 1, 1991 - December 31, 2000

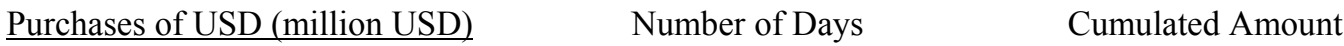

\begin{tabular}{lrr}
$>5000 \mathrm{a}$ & 13 & 100,435 \\
$>1000 \mathrm{~b}$ & 37 & 144,825 \\
$>500 \mathrm{c}$ & 30 & 28,618 \\
$>100 \mathrm{~d}$ & 79 & 22,948 \\
$>\quad 0 \mathrm{e}$ & 9 & 713 \\
Total Purchases & 168 & 303,985 \\
\hline
\end{tabular}

\section{$\underline{\text { Sales of USD (million USD) }}$}

\begin{tabular}{lrr}
$>5000 \mathrm{a}$ & 2 & $-25,757$ \\
$>1000 \mathrm{~b}$ & 3 & $-5,390$ \\
$>500 \mathrm{c}$ & 4 & $-2,295$ \\
$>100 \mathrm{~d}$ & 20 & $-4,043$ \\
$>\quad 0 \mathrm{e}$ & 4 & -273 \\
Total Sales & 33 & $-37,758$ \\
\hline
\end{tabular}

Fed Intervention, April 1, 1991 - December 31, 2000.

Purchases of USD (million USD) $\quad$ Number of Days Cumulated Amount

\begin{tabular}{lrr}
$>5000 \mathrm{a}$ & 0 & 0 \\
$>1000 \mathrm{~b}$ & 0 & 0 \\
$>500 \mathrm{c}$ & 3 & 2,160 \\
$>100 \mathrm{~d}$ & 15 & 5,184 \\
$>\quad 0 \mathrm{e}$ & 0 & 0 \\
Total Purchases & 18 & 7,344 \\
\hline
\end{tabular}

$\underline{\text { Sales of USD (million USD) }}$

\begin{tabular}{lrr}
$>5000 \mathrm{a}$ & 0 & 0 \\
$>1000 \mathrm{~b}$ & 0 & 0 \\
$>500 \mathrm{c}$ & 1 & -833 \\
$>100 \mathrm{~d}$ & 0 & 0 \\
$>\quad 0 \mathrm{e}$ & 3 & -200 \\
Total Sales & 4 & -1.033 \\
\hline
\end{tabular}

a) Daily intervention operations of USD 5000 million or greater.

b) Daily intervention operations of USD 1000 million or greater, but less than USD 5000 million.

c) Daily intervention operations of USD 500 million or greater, but less than USD 1000 million.

d) Daily intervention operations of USD 100 million or greater, but less than USD 500 million.

e) Daily intervention operations of less than USD 100 million. 
Table 2 Total Intervention in the USD/JPY Exchange Rate Market (5-day "tranquillity" definition, 2-day window length)

\begin{tabular}{|c|c|c|c|c|}
\hline Date of event & $\begin{array}{l}\text { Avg. daily \% } \\
\text { change in the } \\
\text { USD/JPY } \\
\text { exchange rate } \\
\text { over } \\
\text { preceding } 2 \\
\text { days (a) }\end{array}$ & $\begin{array}{l}\text { Total amount of } \\
\text { intervention (b) } \\
\text { (millions of USD) }\end{array}$ & $\begin{array}{l}\text { Number of days of } \\
\text { intervention during } \\
\text { event }\end{array}$ & $\begin{array}{l}\text { Avg. daily \% change } \\
\text { in the USD/JPY } \\
\text { exchange rate over } \\
\text { subsequent } 2 \text { days } \\
\text { (c) }\end{array}$ \\
\hline May 13, 91 & -0.143 & -100 & 1 & 0.518 \\
\hline Jun 10, 91 - Jun 13, 91 & -0.421 & -299 & 2 & 0.129 \\
\hline Aug 19, 91 & -0.233 & -101 & 1 & 0.547 \\
\hline Jan 17, 92 & -0.576 & -99 & 1 & 1.717 \\
\hline Feb 17, 92 - Feb 20, 92 & -0.098 & -847 & 2 & -0.174 \\
\hline $\operatorname{Mar}$ 4, $92-\operatorname{Mar} 11,92$ & -0.648 & -291 & 2 & -0.055 \\
\hline Apr 1,92 & 0.075 & -273 & 1 & 0.468 \\
\hline Apr 27, $92-$ Apr 30, 92 & -0.141 & -1253 & 3 & 0.226 \\
\hline May 22, $92-$ Jun 25, 92 & -0.442 & -2455 & 10 & 0.080 \\
\hline Jul 24, 92 -Jul 27, 92 & -0.524 & -374 & 2 & -0.078 \\
\hline Aug 7, 92 - Aug 11, 92 & -0.196 & -125 & 2 & 0.306 \\
\hline Apr 2, 93 - May 7, 93 & 1.099 & 7287 & 17 & -0.311 \\
\hline May 26, 93 - Jun 15, 93 & 0.424 & 9587 & 13 & -0.539 \\
\hline Jun 28, 93 & 1.414 & 99 & 1 & -0.350 \\
\hline Jul 30, $93-$ Sep 7, 93 & 0.028 & 8334 & 18 & -0.543 \\
\hline Feb 15, $94-\operatorname{Mar} 4,94$ & 2.087 & 3817 & 9 & 0.143 \\
\hline Mar 29, 94 - May 4, 94 & 0.670 & 5640 & 16 & -0.351 \\
\hline Jun 20, 94 - Jul 12, 94 & 0.016 & 6338 & 11 & -0.811 \\
\hline Aug 18, $94-$ Aug 25, 94 & -0.105 & 1516 & 6 & -0.169 \\
\hline Sep 6, $94-$ Sep 20, 94 & 0.458 & 800 & 4 & -0.133 \\
\hline Oct 3,94 & -0.141 & 158 & 1 & 0.015 \\
\hline Oct $14,94-$ Nov 3,94 & 0.375 & 4790 & 8 & 0.492 \\
\hline Feb 17, 95 - Apr 18, 95 & 0.563 & 27499 & 34 & -0.930 \\
\hline May 31, 95 & 1.237 & 1250 & 1 & -0.147 \\
\hline Jun 28, 95 - Jul 7, 95 & 0.249 & 1502 & 2 & -0.390 \\
\hline Aug 2, 95 & -0.141 & 7940 & 1 & -0.234 \\
\hline Aug 11, 95 - Aug 15, 95 & -0.569 & 1796 & 2 & -0.598 \\
\hline Sep 6, $95-$ Sep 8, 95 & -0.010 & 10889 & 2 & -0.555 \\
\hline Sep 22, 95 & 2.033 & 6082 & 1 & -1.162 \\
\hline Feb 20, 96 - Feb 27, 96 & 0.672 & 15276 & 5 & -0.357 \\
\hline Dec 17, 97 - Dec 19, 97 & -0.053 & -8242 & 3 & -0.345 \\
\hline Apr 9, 98 - Apr 10, 98 & 0.777 & -21820 & 2 & -0.150 \\
\hline Jun 17,98 & 0.119 & -2512 & 1 & 1.296 \\
\hline Jan 12, 99 & 1.312 & 5856 & 1 & -0.520 \\
\hline Jun 10, 99 - Jun 21, 99 & 0.882 & 20660 & 3 & 0.095 \\
\hline Jul 5, 95 & -0.078 & 6446 & 1 & -0.250 \\
\hline Jul 20, 99 - Jul 21, 99 & 0.553 & 4933 & 2 & 0.744 \\
\hline Sep 10, 99 - Sep 14, 99 & 1.353 & 9474 & 2 & 0.119 \\
\hline Nov $29,99-\operatorname{Nov} 30,99$ & 1.182 & 11104 & 2 & -0.434 \\
\hline Dec 24,99 & 0.163 & 3598 & 1 & 0.372 \\
\hline Jan 4, 00 & 0.309 & 5581 & 1 & -1.003 \\
\hline Mar 8, 00 - Mar 15, 00 & 0.753 & 9425 & 2 & -0.245 \\
\hline Apr 3, 00 & 1.396 & 13217 & 1 & -0.085 \\
\hline \multicolumn{5}{|c|}{$\begin{array}{l}\text { a) Average daily percentage change in the USD/JPY exchange rate over the two business days prior to first day of the } \\
\text { event. }\end{array}$} \\
\hline \multicolumn{5}{|c|}{$\begin{array}{l}\text { b) Positive values represent intervention in support of the USD, i.e. purchase of USD, while negative values represent } \\
\text { intervention aimed at reducing the value of the USD, i.e. sale of USD. }\end{array}$} \\
\hline \multicolumn{5}{|c|}{ c) Average percentage change in the USD/JPY exchange rate over the 2 business days succeeding the last day of the } \\
\hline
\end{tabular}


Table 3 Total Intervention in the USD/JPY Exchange Rate Market (5-day "tranquillity" definition and 2-day event windows)

Non-parametric sign test of "direction"

\begin{tabular}{lccc} 
& $\begin{array}{c}\text { Number of } \\
\text { Events }\end{array}$ & $\begin{array}{c}\text { Number of } \\
\text { Successes (a) }\end{array}$ & P-value (b) \\
\cline { 2 - 4 } USD Purchases & 29 & 22 & $0.41 \%$ \\
USD Sales & 14 & 9 & $21.20 \%$ \\
Total USD Purchases and Sales & 43 & 31 & $0.27 \%$ \\
\hline
\end{tabular}

$\underline{\text { Non-parametric sign test of "reversal" }}$

\begin{tabular}{lccc} 
& $\begin{array}{c}\text { Number of } \\
\text { Events }\end{array}$ & $\begin{array}{c}\text { Number of } \\
\text { Successes (a) }\end{array}$ & P-value (b) \\
\cline { 2 - 4 } USD Purchases when USD Depreciates (c) & 23 & 17 & $1.73 \%$ \\
USD Sales when USD Appreciates (c) & 11 & 7 & $27.44 \%$ \\
Total USD Sales and Purchases (c) & 34 & 24 & $1.22 \%$ \\
\hline
\end{tabular}

Non-parametric sign test of "smoothing"

\begin{tabular}{lccc} 
& $\begin{array}{c}\text { Number of } \\
\text { Events }\end{array}$ & $\begin{array}{c}\text { Number of } \\
\text { Successes (d) }\end{array}$ & P-value (e) \\
\cline { 2 - 4 } USD Purchases when USD Depreciates (c) & 23 & 20 & $13.70 \%$ \\
USD Sales when USD Appreciates (c) & 11 & 9 & $45.52 \%$ \\
Total USD Sales and Purchases (c) & 34 & 29 & $11.38 \%$ \\
\hline
\end{tabular}

a. Intervention is successful if the sale (purchase) of USD is associated with USD depreciation (appreciation) measured as the average of the exchange rate changes over subsequent 2-day period.

b. Based on a binomial probability distribution with the probability of an individual success of $50 \%$.

c. The Bank of Japan and the Fed pursuing a "leaning against the wind" intervention policy.

d. Intervention is successful if the sale (purchase) of USD is associated with USD depreciation (appreciation) or slowing of USD appreciation (depreciation).

e. Based on a binomial probability distribution with the probability of an individual success of $75 \%$. 
Table 4

Total Intervention in the USD/JPY Exchange Rate Market:

5-day "tranquillity" definition, different window lengths and excluding events coinciding with interest rate changes

$\underline{\text { Non-parametric sign test of "direction" }}$

Number of Number of

Events Successes (a) P-value (b)

2-day windows

43

31

$0.27 \%$

5-day windows

43

31

$0.27 \%$

2-day windows; excl. interest rate changes

37

26

$1.00 \%$

5-day windows; excl. interest rate changes

37

25

$2.35 \%$

$\underline{\text { Non-parametric sign test of "reversal" }}$

Number of Number of

Events Successes (a) P-value (b)

2-day windows (c)

34

24

$1.22 \%$

5-day windows (c)

36

26

$0.57 \%$

2-day windows; excl. interest rate changes (c)

30

21

$2.14 \%$

5-day windows; excl. interest rate changes (c)

32

22

$2.51 \%$

Non-parametric sign test of "smoothing"

\begin{tabular}{lccc}
\hline & $\begin{array}{c}\text { Number of } \\
\text { Events }\end{array}$ & $\begin{array}{c}\text { Number of } \\
\text { Successes (d) }\end{array}$ & P-value (e) \\
\cline { 2 - 4 } 2-day windows (c) & 34 & 29 & $11.38 \%$ \\
5-day windows (c) & 36 & 35 & $0.04 \%$ \\
2-day windows; excl. interest rate changes (c) & 30 & 25 & $20.26 \%$ \\
5-day windows; excl. interest rate changes (c) & 32 & 31 & $0.12 \%$ \\
\hline
\end{tabular}

a. Intervention is successful if the sale (purchase) of USD is associated with USD depreciation (appreciation) measured as the average of the exchange rate changes over subsequent period.

b. Based on a binomial probability distribution with the probability of an individual success of $50 \%$.

c. The Bank of Japan and the Fed pursuing a "leaning against the wind" intervention policy.

d. Intervention is successful if the sale (purchase) of USD is associated with USD depreciation (appreciation) or slowing of USD appreciation (depreciation).

e. Based on a binomial probability distribution with the probability of an individual success of $75 \%$. 
Matched sample test of "smoothing"

Number of

Events

USD Purchases

Difference in means

USD Purchases when USD Depreciates (b)

Prior event average percentage change (c)

Post event average percentage change (c)

Difference in means

29

23
$-0.91$

$-32.61$

0.84

$-0.28$

$-1.12$

$-32.91$

14

Difference in means

USD Sales when USD Appreciates (b)

11

Prior event average percentage change (c) $\quad-0.32$

$\begin{array}{ll}\text { Post event average percentage change (c) } & 0.26\end{array}$

Difference in means

0.58

9.29

a. Matched sample (paired comparison) of exchange rate growth rate changes prior and post of each event, assuming both series are normally distributed.

b. The Bank of Japan and the Fed pursuing a "leaning against the wind" intervention policy.

c. The average of the average daily percentage change in the exchange rate over preceding and subsequent 2 days, respectively. 
Table 6

Interest Rate Changes During Events (5-day "tranquillity" definition)

\begin{tabular}{|c|c|c|c|c|}
\hline Date of event & Interest Rate Change & Total Intervention $^{\mathrm{a}}$ & Date of Change & Consistency $^{b}$ \\
\hline Apr 1, 92 & $-0.75(\mathrm{JPD})$ & -273 & Apr 1, 92 & No \\
\hline Jul 24, 92 - Jul 27, 92 & $-0.50(\mathrm{JPD})$ & -374 & Jul 27, 92 & No \\
\hline Mar 29, 94 - May 4, 94 & $+0.25(\mathrm{FF})$ & 5640 & Apr 18, 94 & Yes \\
\hline Feb 17, 95 - Apr 18, 95 & $-0.75(\mathrm{JPD})$ & 27499 & Apr 14, 95 & Yes \\
\hline Jun 28, 95 - Jul 7, 95 & $-0.25(\mathrm{FF})$ & 1502 & Jul 6, 95 & No \\
\hline Sep 6, 95 - Sep 8, 95 & $-0.5(\mathrm{JPD})$ & 10889 & Sep 8, 95 & Yes \\
\hline
\end{tabular}

a) Positive values represent intervention in support of the USD, i.e. purchase of USD, while negative values represent intervention aimed at reducing the USD, i.e. sale of USD.

b) The direction of the intervention operation is consistent with the direction of the interest rate change, e.g. a purchase of USD is consistent with a rise in the Federal Funds target rate (FF) and/or a fall in the Japanese discount rate (JPD). 
Table 7

Total Intervention in the USD/JPY Exchange Rate Market: 5-day "tranquillity" definition, different window lengths and excluding events coinciding with WSJ reports and rumours of intervention

$\underline{\text { Non-parametric sign test of "direction" }}$

Number of Number of

Events Successes (a) P-value (b)

2-day windows; excl. reported events

9

7

$8.98 \%$

5-day windows; excl. reported events

9

8

$1.95 \%$

2-day windows; excl. reported and rumored events

5

4

$18.75 \%$

5-day windows; excl. reported and rumored events

5

4

$18.75 \%$

$\underline{\text { Non-parametric sign test of "reversal" }}$

\begin{tabular}{lccc}
\hline & $\begin{array}{c}\text { Number of } \\
\text { Events }\end{array}$ & $\begin{array}{c}\text { Number of } \\
\text { Successes (a) }\end{array}$ & P-value (b) \\
\cline { 2 - 4 } 2-day windows; excl. reported events & 7 & 5 & $22.66 \%$ \\
5-day windows; excl. reported events & 7 & 6 & $6.25 \%$ \\
2-day windows; excl. reported and rumored events & 3 & 2 & $50.00 \%$ \\
5-day windows; excl. reported and rumored events & 3 & 2 & $50.00 \%$ \\
\hline
\end{tabular}

Non-parametric sign test of "smoothing"

\begin{tabular}{lccc}
\hline & $\begin{array}{c}\text { Number of } \\
\text { Events }\end{array}$ & $\begin{array}{c}\text { Number of } \\
\text { Successes (d) }\end{array}$ & P-value (e) \\
\cline { 2 - 4 } 2-day windows; excl. reported events & 7 & 6 & $44.49 \%$ \\
5-day windows; excl. reported events & 7 & 7 & $13.35 \%$ \\
2-day windows; excl. reported and rumored events & 3 & 2 & $84.38 \%$ \\
5-day windows; excl. reported and rumored events & 3 & 3 & $42.19 \%$ \\
\hline
\end{tabular}

a. Intervention is successful if the sale (purchase) of USD is associated with USD depreciation (appreciation) measured as the average of the exchange rate changes over subsequent period.

b. Based on a binomial probability distribution with the probability of an individual success of $50 \%$.

c. The Bank of Japan and the Fed pursuing a "leaning against the wind" intervention policy.

d. Intervention is successful if the sale (purchase) of USD is associated with USD depreciation (appreciation) or slowing of USD appreciation (depreciation).

e. Based on a binomial probability distribution with the probability of an individual success of $75 \%$. 
Table 8

Total Intervention in the USD/JPY Exchange Rate Market: 15-day "tranquillity" definition and different window lengths

$\underline{\text { Non-parametric sign test of "direction" }}$

\begin{tabular}{lccc}
\hline & $\begin{array}{c}\text { Number of } \\
\text { Events }\end{array}$ & $\begin{array}{c}\text { Number of } \\
\text { Successes (a) }\end{array}$ & P-value (b) \\
\cline { 2 - 4 } 2-day window definition & 27 & 21 & $0.30 \%$ \\
5-day window definition & 27 & 20 & $0.96 \%$ \\
10-day window definition & 27 & 20 & $0.96 \%$ \\
15-day window definition & 27 & 20 & $0.96 \%$ \\
\hline
\end{tabular}

$\underline{\text { Non-parametric sign test of "reversal" }}$

\begin{tabular}{lccc}
\hline & $\begin{array}{c}\text { Number of } \\
\text { Events }\end{array}$ & $\begin{array}{c}\text { Number of } \\
\text { Successes (a) }\end{array}$ & P-value (b) \\
\cline { 2 - 4 } 2-day window definition (c) & 22 & 18 & $0.22 \%$ \\
5-day window definition (c) & 25 & 18 & $2.16 \%$ \\
10-day window definition (c) & 26 & 19 & $1.45 \%$ \\
15-day window definition (c) & 24 & 17 & $3.20 \%$ \\
\hline
\end{tabular}

Non-parametric sign test of "smoothing"

\begin{tabular}{lccc}
\hline & $\begin{array}{c}\text { Number of } \\
\text { Events }\end{array}$ & $\begin{array}{c}\text { Number of } \\
\text { Successes (d) }\end{array}$ & P-value (e) \\
\cline { 2 - 4 } 2-day window definition (c) & 22 & 21 & $1.49 \%$ \\
5-day window definition (c) & 25 & 23 & $3.21 \%$ \\
10-day window definition (c) & 26 & 24 & $2.58 \%$ \\
15-day window definition (c) & 24 & 22 & $3.98 \%$ \\
\hline
\end{tabular}

a. Intervention is successful if the sale (purchase) of USD is associated with USD depreciation (appreciation) measured as the average of the exchange rate changes over subsequent period.

b. Based on a binomial probability distribution with the probability of an individual success of $50 \%$.

c. The Bank of Japan and the Fed pursuing a "leaning against the wind" intervention policy.

d. Intervention is successful if the sale (purchase) of USD is associated with USD depreciation (appreciation) or slowing of USD appreciation (depreciation).

e. Based on a binomial probability distribution with the probability of an individual success of $75 \%$. 

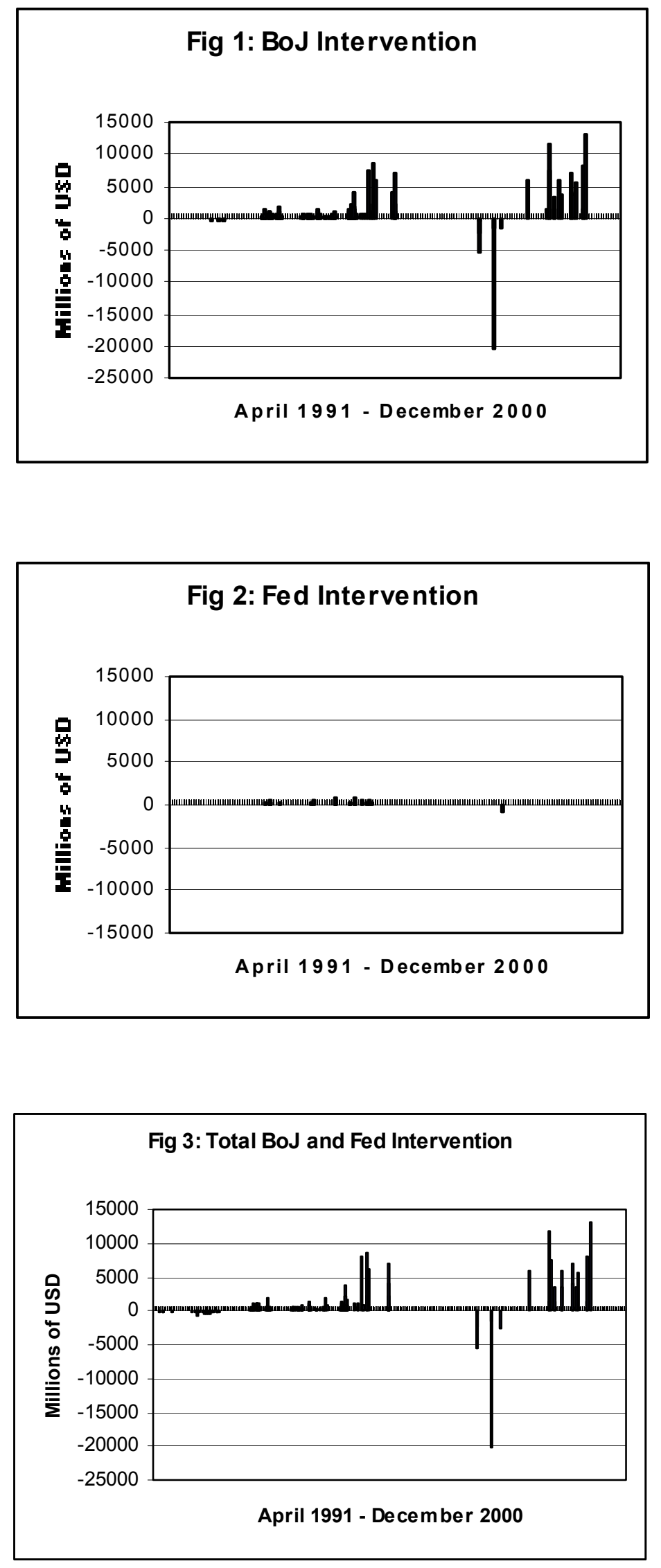